\title{
Long-Term Observations and High-Resolution Modeling of Midlatitude Nocturnal Boundary Layer Processes Connected to Low-Level Jets
}

\author{
Tobias Marke, Susanne Crewell, Vera Schemann, and Jan H. Schween \\ Institute for Geophysics and Meteorology, University of Cologne, Cologne, Germany \\ MinTtu TUONONEN \\ Finnish Meteorological Institute, Helsinki, and Vaisala Oyj, Vantaa, and Department of Physics, University of Helsinki, \\ Helsinki, Finland
}

(Manuscript received 6 December 2017, in final form 9 March 2018)

\begin{abstract}
Low-level-jet (LLJ) periods are investigated by exploiting a long-term record of ground-based remote sensing Doppler wind lidar measurements supported by tower observations and surface flux measurements at the Jülich Observatory for Cloud Evolution (JOYCE), a midlatitude site in western Germany. LLJs were found $13 \%$ of the time during continuous observations over more than $4 \mathrm{yr}$. The climatological behavior of the LLJs shows a prevailing nighttime appearance of the jets, with a median height of $375 \mathrm{~m}$ and a median wind speed of $8.8 \mathrm{~m} \mathrm{~s}^{-1}$ at the jet nose. Significant turbulence below the jet nose only occurs for high bulk wind shear, which is an important parameter for describing the turbulent characteristics of the jets. The numerous LLJs ( $16 \%$ of all jets) in the range of wind-turbine rotor heights below $200 \mathrm{~m}$ demonstrate the importance of LLJs and the associated intermittent turbulence for wind-energy applications. Also, a decrease in surface fluxes and an accumulation of carbon dioxide are observed if LLJs are present. A comprehensive analysis of an LLJ case shows the influence of the surrounding topography, dominated by an open pit mine and a $200-\mathrm{m}$-high hill, on the wind observed at JOYCE. High-resolution large-eddy simulations that complement the observations show that the spatial distribution of the wind field exhibits variations connected with the orographic flow depending on the wind direction, causing high variability in the long-term measurements of the vertical velocity.
\end{abstract}

\section{Introduction}

One of the dominant nocturnal atmospheric boundary layer processes over land areas is the decoupling of the lower troposphere from the friction-governed surface layer, leading to the formation of a distinct maximum in the vertical profile of the horizontal wind speed, called a low-level jet (LLJ). The nighttime development of a stable surface layer results in a decrease in surface friction in the decoupled residual layer above and hence an inertial oscillation (Blackadar 1957). The wind speed maximum of LLJs is typically found between 100 and $1000 \mathrm{~m}$ (Tuononen et al. 2015), and the wind shear below this jet maximum leads to the generation of turbulence (Banta et al. 2002). Turbulent motions related to the LLJs are often intermittent and highly energetic, which is crucial for wind-energy applications (Emeis et al.

\footnotetext{
Corresponding author: Tobias Marke, tmarke@meteo.uni-koeln.
} de
2007; Peña et al. 2016). Especially in the region of the rotor height, LLJ events can have an impact on the performance and lifetime of a wind turbine (Zhou and Chow 2012). On the other hand, the increased wind speed makes places with frequently occurring LLJs, such as the Great Plains region, favorable for windenergy production (Storm et al. 2009).

LLJs can also be associated with local transport of aerosols and water vapor, controlling the evolution of clouds and precipitation by horizontal convergence and uplifting of atmospheric constituents ( $\mathrm{Su}$ et al. 2016). The transferring motions and moisture transport between the surface and the atmosphere also directly affect synoptic-scale systems, leading to changes in precipitation patterns (Higgins et al. 1997). At the surface, the momentum decoupling during nighttime LLJs can reduce surface fluxes, leading to an accumulation of atmospheric gases (Mathieu et al. 2005). This process is limited by intermittent turbulence that reaches the surface and hence weakens the stabilization and depth of 
the nocturnal boundary layer. The correct representation of LLJ-related turbulence effects is therefore crucial for predictions in atmospheric weather and climate models at different resolutions (Stensrud 1996; Holtslag et al. 2013).

The forcing mechanisms of continental LLJs in the midlatitudes have been extensively studied, especially in the Great Plains (Mitchell et al. 1995; Zhong et al. 1996), and a more complete review can be found in Stensrud (1996). The identification of LLJs in earlier studies was based on radiosonde observations (Bonner 1968; Whiteman et al. 1997) or meteorological-tower measurements (Dörenkämper et al. 2015). Even though these observations provide good vertical resolution, they are lacking in temporal resolution (radiosondes) and vertical extent (towers). Therefore, many previous studies have utilized remotely sensing radio acoustic or (ultra-high frequency) radar wind profilers to obtain detailed case analyses and continuous long-term records of LLJs (e.g., Baas et al. 2009; Lampert et al. 2016; Mitchell et al. 1995). Doppler wind lidars (DWLs), which are an emerging tool in ground-based remote sensing networks such as the European Earth System Science and Environmental Management European Cooperation in Science and Technology (COST) Action ES1303 network or the ground-based remote sensing network in Finland (Hirsikko et al. 2014), show considerable potential for observing winds and turbulent parameters at high spatial and temporal resolution. The study by Tuononen et al. (2017) showed the capability of a DWL to identify LLJs for a multiyear dataset, and Lampert et al. (2015) used a 1-yr dataset to derive statistics related to LLJ occurrence and parameters of the Weibull distribution. By continuously providing accurate estimates of the vertical wind component, DWLs are furthermore able to quantify turbulent motions (O'Connor et al. 2010) and detect clouds and the aerosol layer.

In this study, long-term (2012-16) DWL measurements at the Jülich Observatory for Cloud Evolution (JOYCE; Löhnert et al. 2015) in western Germany are used together with a detailed case analysis, combining groundbased remote sensing, radiosondes (RS), and large-eddy simulation (LES) model output, to investigate local nocturnal boundary layer processes. The research focus of this study encompasses the climatological behavior (or "climatology") of LLJs, their turbulence characteristics, and their influence on the surface fluxes using a long-term record of DWL, tower, and eddy-covariance (EC) measurements. A detailed case analysis reveals the local LLJ effects related to the topography by observations and LES. The chosen case analysis was carried out during the High Definition Cloud and Precipitation for Advancing
Climate Prediction $\left[\mathrm{HD}(\mathrm{CP})^{2}\right]$ Observational Prototype Experiment (HOPE) field campaign in April and May of 2013 (Macke et al. 2017). The HOPE campaign was conducted to provide ground-based information on land surface-atmosphere interactions including clouds and precipitation in the boundary layer and to evaluate the LES extension of the atmospheric Icosahedral Nonhydrostatic (ICON) model (Dipankar et al. 2015).

This article is built in the following way. Section 2 describes the measurement site, including the deployed instruments utilized in this study. Subsequently in section 3 the dataset of the DWL is introduced together with the LLJ identification and the model setup. The results of the LLJ climatology, the turbulence characteristics, and the surface fluxes are presented and discussed in section 4 , followed by the case analysis during the HOPE campaign that investigates topographic effects supported by LES in section 5. A summary is given and conclusions about the presented results are drawn in section 6 .

\section{Description of measurement site and instruments}

\section{a. JOYCE site and supporting instruments}

The observational data are provided by the JOYCE site located in western Germany $\left(50^{\circ} 54^{\prime} 31^{\prime \prime} \mathrm{N}, 6^{\circ} 24^{\prime} 49^{\prime \prime} \mathrm{E}\right.$ at $111 \mathrm{~m} \mathrm{MSL}$; Fig. 1a), which is operated jointly by the Institute for Geophysics and Meteorology at the University of Cologne, the Meteorological Institute of the University of Bonn, and the Institute of Energy and Climate Research (IEK-8) at the Forschungszentrum Jülich. The JOYCE supersite is embedded in a rural environment with different crop types and provides a constantly growing multiyear dataset for detailed insight into boundary layer processes and patterns related to surface conditions (Löhnert et al. 2015). The mostly flat topography is dominated by two open-pit mines east and southwest of the site and a mine dump hill (Sophienhöhe), $200 \mathrm{~m}$ higher than the JOYCE site, to the northeast (Fig. 1c). A plain at around $100 \mathrm{~m}$ MSL stretches from southeast to northwest, including a riverbed of the Rur River and with a slight slope to the northwest. Together with the Eifel region, which is approximately $20 \mathrm{~km}$ to the south with hills of around $800 \mathrm{~m}$ MSL (Fig. 1b), the valley shows a potential channeling effect of the wind, with the Sophienhöhe as a northeast border. In a circle of $1 \mathrm{~km}$ around the JOYCE site, the topography shows a maximum height of $120.3 \mathrm{~m}$ MSL and a standard deviation of $5.7 \mathrm{~m}$. The maximum height increases to $296.6 \mathrm{~m}$ MSL with a standard deviation of $48.9 \mathrm{~m}$ for a $5-\mathrm{km}$ circle. 
a)

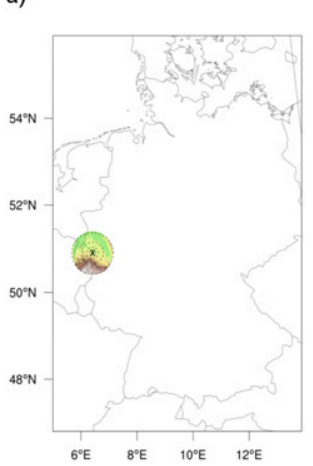

b)

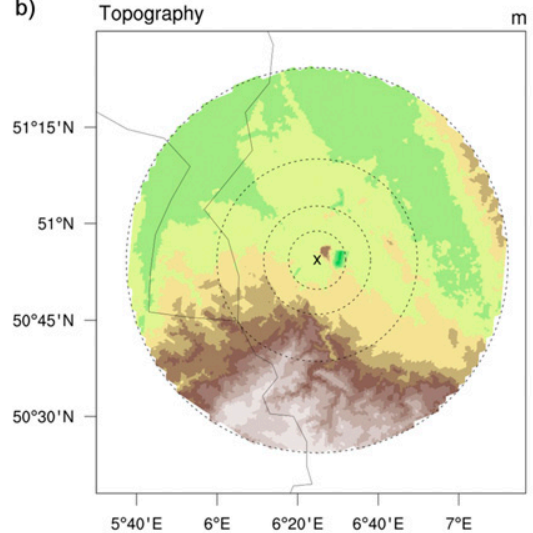

c)

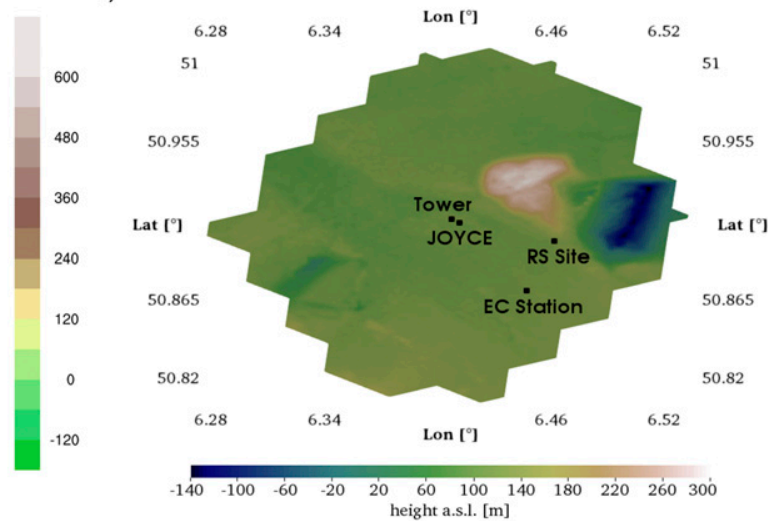

FIG. 1. (a) Location and (b) topographic maps of the ICON-LEM circular domains and the position of the JOYCE site (black X) within Germany. (c) A segment of the innermost domain (10-km radius and 78-m horizontal resolution) centered around the JOYCE site, also indicating the measurement sites and instruments deployed in this study.

The majority of the JOYCE instrumentation has been operational since 2012 and includes a DWL, cloud radar, microwave radiometer, and ceilometer. The long-term and continuous dataset of JOYCE provides temporal highly resolved cloud micro- and macrophysical observations, as well as a characterization of the environment in which they evolve. As an additional observational support during the HOPE campaign, from two to seven radiosonde launches per day were conducted from a nearby station. The launch site of the radiosondes (labeled as "RS Site" in Fig. 1) is located $3.8 \mathrm{~km}$ east of the site at the southeastern corner of the Sophienhöhe.

A 120-m-high meteorological tower is located approximately $330 \mathrm{~m}$ northwest of JOYCE (labeled as "Tower" in Fig. 1). The tower is equipped with cup anemometers and wind vanes at 30,50, and $120 \mathrm{~m}$, allowing simultaneous measurement of the wind speed and the wind direction. To observe the atmosphere-land surface interactions, several EC stations are deployed around JOYCE. For this study, the EC station at the agricultural flatland site Selhausen is used, which is located $5 \mathrm{~km}$ southeast of the JOYCE site (labeled as "EC Station" in Fig. 1). The measurement devices (sonic anemometer and open-path gas analyzer) are deployed at a height of $2.46 \mathrm{~m}$ above the ground. The averaging interval of the data obtained with a measurement frequency of $20 \mathrm{~Hz}$ is set to $30 \mathrm{~min}$, and the quality assessment and quality control of the measurements, together with the instrument setup, are explained in Mauder et al. (2013).

\section{b. Doppler wind lidar}

The Halo Photonics Streamline DWL (Pearson et al. 2009), the main instrument for this study, was installed on the roof of the IEK- 8 building, which is referred to as the JOYCE site. The DWL measures the backscattered light from an emitted laser beam at $1.5 \mu \mathrm{m}$. The analysis of the Doppler shift provides an estimate of the wind speed along the line of sight. The combination of several inclined beams allows the derivation of the three components of the wind vector and therefore also the wind direction. The attenuated backscatter coefficient can be calculated by the amount of received backscattered light, which mainly depends on the number and size of aerosol and/or cloud particles in the measured volume.

At JOYCE the DWL operational schedule consists of four conical scans per hour with 36 beams at $75^{\circ}$ elevation and a duration of approximately $3 \mathrm{~min}$. This velocity azimuth display method provides accurate wind estimates, even in turbulent situations (Päschke et al. 2015). For the remainder of the hour, the instrument points vertically, with a temporal resolution of $1.67 \mathrm{~s}$. The vertical measurements provide profiles of the vertical velocity, which in turn can be used for turbulence estimates by calculating the standard deviation for each range gate (Schween et al. 2014). The vertical resolution is $30 \mathrm{~m}$, with the first reliable range gate, as determined by the signal-to-noise ratio, usually at $105 \mathrm{~m}$ above the instrument (fourth range gate).

\section{Data and methods}

The DWL at JOYCE has been measuring continuously since March of 2012, and the LLJ classification, described in the following section, was applied through the end of 2016. Because of measurement gaps, the resulting dataset contains 1518 days of DWL observations that are analyzed in this study. The HOPE campaign at JOYCE was conducted from 3 April to 31 May 2013 to study the frequently occurring formation of boundary layer cloud during the spring season. 


\section{a. Low-level jet detection}

In previous studies various criteria were used to detect LLJs in long-term observations to compile an LLJ climatology. In the study by Bonner (1968), LLJs are identified by detecting a wind speed maximum and a $50 \%$ decrease above the jet in the lowest $3 \mathrm{~km}$. The LLJ detection algorithm of Baas et al. (2009) uses an absolute and relative criterion for the wind speed maximum and the corresponding minimum above, which is also used in a similar way in Lampert et al. (2015).

In this study, the LLJ identification of Tuononen et al. (2017) is applied to the DWL measurements between 2012 and 2016. In addition, tower measurements at 30 and $50 \mathrm{~m}$ are used to fill the observational gap of the DWL below $105 \mathrm{~m}$. A comparison of hourly averaged wind speed measurements during nighttime at $120 \mathrm{~m}$ from the tower and the DWL vertical profile reveals a high correlation of 0.95 during the observational period (not shown). Despite the high correlation, the tower measurements are only used when the wind speed difference to the DWL at $120 \mathrm{~m}$ does not exceed $2 \mathrm{~m} \mathrm{~s}^{-1}$. In this way, false classifications due to large deviations between the tower and DWL can be avoided, as a smooth transition of the wind speed between the tower and DWL is ensured and about $13 \%$ of the otherwise detected LLJs are neglected.

The LLJ identification algorithm requires a relative and an absolute criterion to be fulfilled to detect an LLJ. The maximum wind speed in each profile must be at least $2 \mathrm{~m} \mathrm{~s}^{-1}$ higher and $25 \%$ stronger than the minimum above and below the jet between 30 and $1485 \mathrm{~m}$. In this way small variations in weak wind situations and turbulent fluctuations for stronger winds are prevented from being falsely identified as an LLJ.

After this first step of LLJ identification, the following consistency checks are applied to distinguish between a temporal and spatial continuation of an LLJ and a newly formed LLJ. For an LLJ continuation, the strength and direction of the LLJ maximum should not change by more than $30 \%$ and $45^{\circ}$, respectively, between two consecutive profiles measured every $15 \mathrm{~min}$ and the LLJ height should stay within four range gates $(120 \mathrm{~m})$. In addition to the algorithm of Tuononen et al. (2017), it is required that no data gaps occur between two detected wind speed maxima. Only coherent LLJs that are persistent for at least $1 \mathrm{~h}$ are considered. The LLJ speed and direction in this study refer to the measured value at the location of the wind speed maximum, which is referred to as the LLJ height or jet nose.

\section{b. ICON-LEM}

The ICON model (Zängl et al. 2015) was developed in a collaboration between the German Weather Service
[Deutscher Wetterdienst (DWD)] and the Max Planck Institute for Meteorology (MPI-M) as a new modeling system. Within the framework of the $\operatorname{HD}(\mathrm{CP})^{2}$ project, the ICON Large-Eddy Model (ICON-LEM) was designed to conduct LES over the whole of Germany to improve moist processes in climate prediction models (Heinze et al. 2017) and is still under development. In this study, the ICON-LEM simulation of one day (2 May 2013) is used to compare with measurements obtained from the HOPE campaign in Jülich and to provide a spatial representation of the wind field. ICON-LEM has already proven to be in agreement with HOPE observations concerning turbulence, column water vapor, and cumulus clouds (when compared with satellite observations), especially for higher grid resolutions (Heinze et al. 2017).

Here, a setup that is similar to that of Heinze et al. (2017) is used and includes four nests with circular domains centered around JOYCE (Fig. 1b). The nests start with a radius of $110 \mathrm{~km}$ and a horizontal resolution of $624 \mathrm{~m}$ and end with a radius of $10 \mathrm{~km}$ and a horizontal resolution of $78 \mathrm{~m}$, which is used in this study. The vertical extent of the simulated domain is about $20 \mathrm{~km}$, with a minimal layer thickness of $20 \mathrm{~m}$ and 33 levels in the lowest $2 \mathrm{~km}$. The operational COSMO model covering the German domain (COSMO-DE), as described in Baldauf et al. (2011), is used as forcing data. The utilized model domain with the highest horizontal resolution $(78 \mathrm{~m})$, together with the implementation of the topography, can be seen in Fig. 1. The simulation is stored as profiles for the JOYCE site with a 9-s output time and as 3D fields for the whole domain every $10 \mathrm{~min}$. The simulations of this study were conducted on the general purpose Jülich Research on Exascale Cluster Architectures (JURECA) supercomputer, which is operated by the Jülich Supercomputing Centre (JSC) at Forschungszentrum Jülich (Krause and Thörnig 2016). The visualizations of the ICON-LEM model domain are realized using the ParaView software package (Ayachit 2015).

\section{Statistical analysis of LLJs}

Before evaluating specific nocturnal boundary layer processes related to the presence of LLJs measured by an EC station in section $4 \mathrm{~b}$, the climatology and statistics of LLJs and their turbulent properties are analyzed.

\section{a. Climatology of LLJs and their turbulent characteristics}

The application of the LLJ detection to the DWL measurements (1518 analyzed days) results in 1020 days 


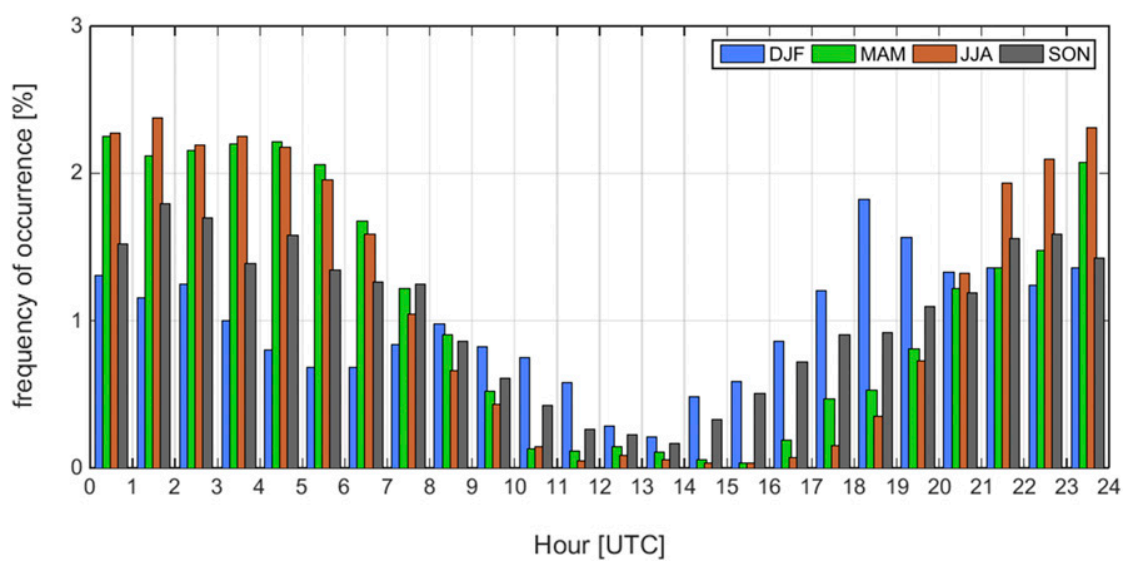

FIG. 2. LLJ frequency of occurrence per hour of the day and for each season relative to the total amount of detected LLJs at JOYCE [local time $=\mathrm{UTC}+1 \mathrm{~h}$ (winter) or $2 \mathrm{~h}$ (summer)]. For an equal number of the different seasons, only LLJs between March 2012 and February 2015 are considered. Total frequencies of occurrence per season are $23 \%$ for DJF, $26 \%$ for MAM, 26\% for JJA, and $25 \%$ for SON.

with a detected LLJ of more than $1 \mathrm{~h}$. The data sample includes 1958 periods of continuously detected LLJs, encompassing 17987 vertical wind profiles and a total frequency of occurrence of $13 \%$ during the observational period. In general, the relative occurrence of LLJs reveals a clear diurnal cycle with fewer LLJs during daytime (Fig. 2). The median LLJ height and wind speed during the observational period are $375 \mathrm{~m}$ and $8.8 \mathrm{~m} \mathrm{~s}^{-1}$, respectively.

When sorting all detected LLJs according to the different seasons between March 2012 and February 2015 for an equality of the seasons, it is evident from Fig. 2 that the lowest occurrence of LLJs $(23 \%)$ is during the winter months [December-February (DJF)]. This result is probably due to a weaker diurnal cycle and therefore a less pronounced temperature difference between day and night, which hampers the jet formation. Also, cloud occurrence is higher in winter, as determined by a $905-\mathrm{nm}$ Vaisala, Inc., CT25k ceilometer at JOYCE, with a mean daily cloud cover of 0.62 as compared with 0.50 for March-May (MAM), 0.47 for June-August (JJA), and 0.55 for September-November (SON). The higher cloud occurrence leads to less radiative cooling in the evening, which is necessary for a decoupling from the friction-governed surface layer and leads to fewer LLJs on winter nights. Between sunrise and sunset, however, the higher cloud cover reduces convective motions and thus the coupling strength, which in turn increases the chance of an LLJ to form. During the shorter daylight period in DJF and SON, LLJ occurrence is increased relative to the summer season, and the peak in wintertime LLJs appears during the evening transition time around 1800 UTC.
The spring (MAM), summer (JJA), and autumn (SON) diurnal cycles are similar, with a slight shift in the decrease in LLJ occurrence in the morning hours and an increase during the evening transition as a result of the different sunrise and sunset times. The relative occurrence in SON is less than in spring and summer during the night, whereas MAM and JJA have the fewest daytime appearances of LLJs. This seasonal difference in LLJ occurrence is in agreement with the LLJ climatology of Baas et al. (2009) at a topographically flat site approximately $200 \mathrm{~km}$ away from JOYCE. The differences are explained by a stronger coupling of the boundary layer and the surface in summer during daytime, resulting in a larger amplitude of the nocturnal inertial oscillation. In winter, the higher frequency of cloudy periods with more geostrophic forcing and weaker stable stratification leads to a lower occurrence of LLJs. The results in Fig. 2 are also in good agreement with those from the study by Lampert et al. (2015) for a 1-yr dataset obtained from a similar site that is located $300 \mathrm{~km}$ northeast of JOYCE. Note that even such details as the early-morning and late-evening relative maxima in winter occur (see Fig. 5 in Lampert et al. 2015).

A further distinction in the forcing mechanisms of the LLJs is reflected in the distribution of the LLJ direction in comparison with the prevailing wind direction at the median height of all LLJs $(375 \mathrm{~m})$. In DJF (and in a similar way for SON) a bimodal distribution of southwesterly-westerly $\left(220^{\circ}-280^{\circ} ; 55 \%\right.$ of all DJF cases) and southeasterly $\left(105^{\circ}-165^{\circ} ; 25 \%\right.$ of all DJF cases) jets can be identified (Fig. 3d), with southwest being the main wind direction at JOYCE in summer and winter (Figs. 3a,b). To relate the observed LLJ wind directions 

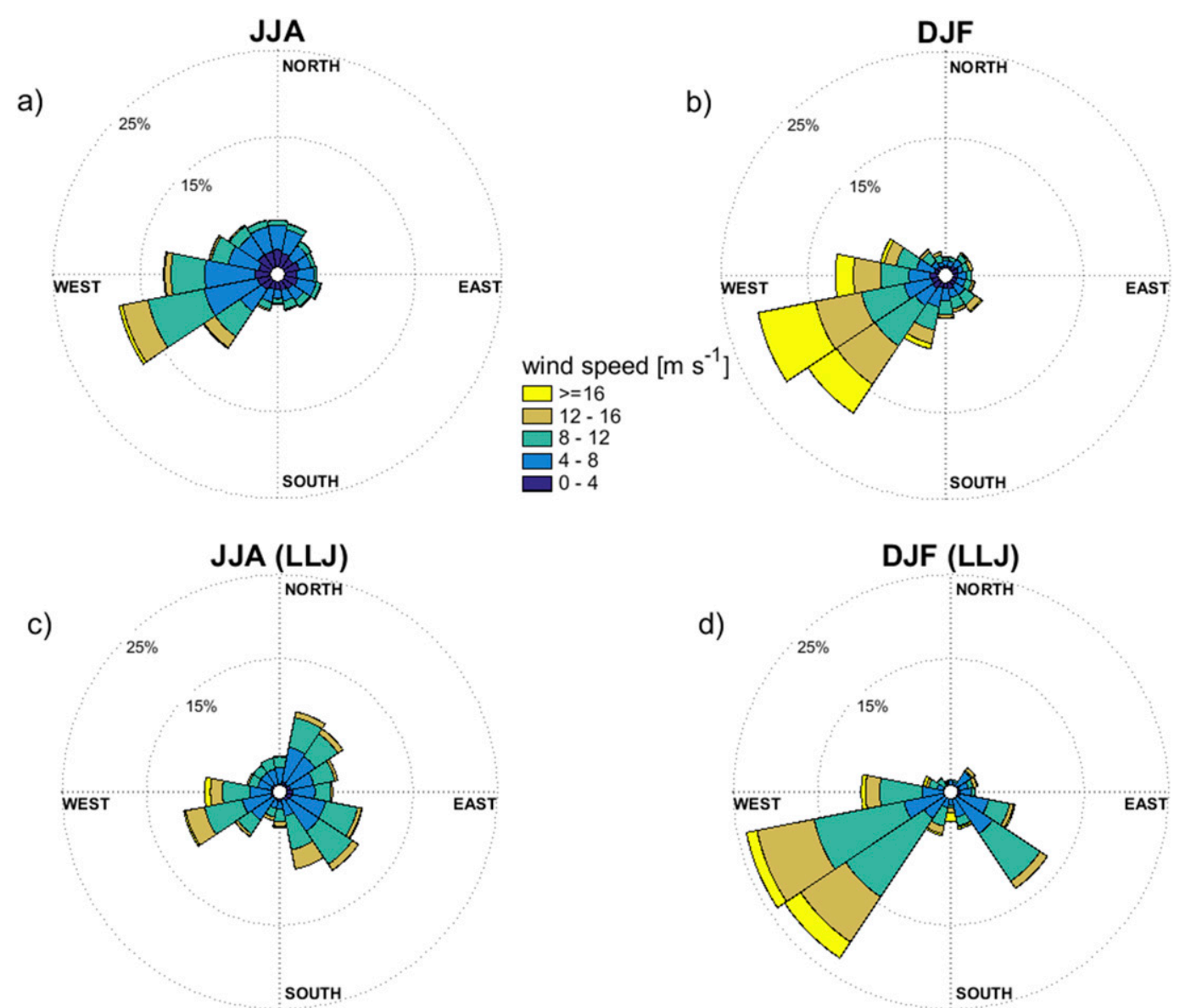

FIG. 3. Wind direction (wind rose) and wind speed (color code) measured at (a),(b) $375 \mathrm{~m}$ and (c),(d) the LLJ core at JOYCE between March 2012 and December 2016. The wind roses show results for (left) JJA and (right) DJF.

to the synoptic situation, the $975-\mathrm{hPa}$ geopotential height of the reanalysis product known as ERA-Interim (Dee et al. 2011) is implemented in the JenkinsonCollison circulation weather type (CWT) classification (Jenkinson and Collison 1977) using the "COST 733" software (Philipp et al. 2016). The CWT model estimates the prevailing wind direction $(\mathrm{W}, \mathrm{NW}, \mathrm{N}, \mathrm{NE}, \mathrm{E}$, SE, S, or SW) or the type of circulation [cyclonic (C) or anticyclonic (AC)] four times per day $(0000,0600,1200$, and 1800 UTC). The CWTs are estimated on the basis of the variability of 16 grid points around the JOYCE site with an extent of $5^{\circ}$ east-west $\times 3^{\circ}$ north-south.

Overall, about $50 \%$ of the CWT classes are detected as $\mathrm{W}$ and $\mathrm{SW}$, which is in agreement with the wind roses in Figs. 3a and 3b. The southwest LLJs can therefore be related to the forcing of common southwesterly winds with low pressure to the northwest and high pressure to the southeast. Only $6 \%$ of all CWT classes are identified as SE for all wintertime LLJs and 9\% for the summertime LLJs. The LLJs originating from this sector (Figs. 3c,d) thus cannot be explained by synoptic forcing, but are most probably connected to a channeling effect by the wide Rur River valley from southeast to northwest. For JJA (and similar for MAM) the distribution of the LLJ direction is broader (Fig. 3c), with a third peak in the northeast $\left(10^{\circ}-70^{\circ} ; 21 \%\right.$ of all JJA cases $)$ connected to an NE circulation weather type, detected in $15 \%$ of the summertime LLJ cases. It is also evident that the months DJF have higher wind speeds, since the LLJ speed is higher than $12 \mathrm{~m} \mathrm{~s}^{-1}$ in $26 \%$ of all cases in DJF and only in $12 \%$ of all cases in JJA. The median jet speeds are $8.3 \mathrm{~m} \mathrm{~s}^{-1}$ for JJA and $9.8 \mathrm{~m} \mathrm{~s}^{-1}$ for DJF, and the median LLJ heights in JJA (375 m) and DJF (345 m) only differ by one DWL range gate.

For the height of the LLJ maximum in the whole observational time period of March 2012-December $2016,87 \%$ of the LLJs have their wind speed maximum below $600 \mathrm{~m}$ (Fig. 4a) and 2965 (16\%) LLJs occurred below $200 \mathrm{~m}$, which is within the range of wind-turbine rotors. Intermittent turbulence in this region could increase turbine loading through wind shear over the area of the rotor (Peña et al. 2016). For the purpose of 


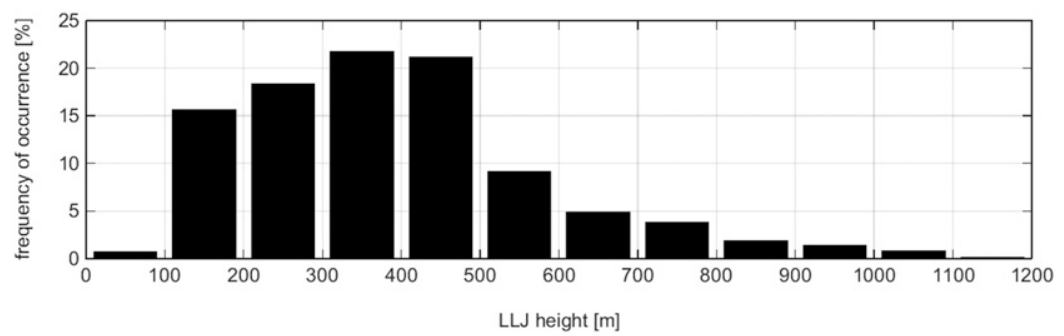

b)

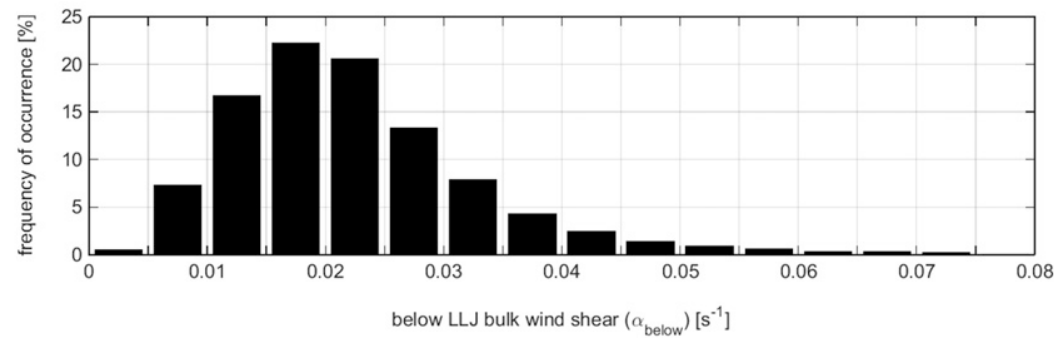

FIG. 4. (a) Height of the LLJ maximum wind speed (bin size $=100 \mathrm{~m}$ ) and (b) below-LLJ bulk wind shear $\alpha_{\text {below }}$ (bin size $=0.005 \mathrm{~s}^{-1}$ ). The data sample contains all detected LLJs between March 2012 and December 2016 at JOYCE.

analyzing the generation of turbulence below the LLJ as an important attribute for wind-energy applications, the dataset is classified according to the bulk wind shear below the jet, similar to Tuononen et al. (2017):

$$
\alpha_{\text {below }}=\frac{U_{\text {LLJ }}-U_{\text {min,below }}}{h_{\text {LLJ }}-h_{\text {min,below }}}
$$

where $U_{\mathrm{LLJ}}$ is the wind speed maximum at the height $h_{\mathrm{LLJ}}$ and $U_{\text {min,below }}$ is the detected wind speed minimum below the jet with the height $h_{\text {min,below }}$.

To investigate the directional shear, vertical profiles of the vector wind shear $U_{\text {shear }}$ can be derived as

$$
U_{\text {shear }}=\frac{\left(\delta u^{2}+\delta v^{2}\right)^{1 / 2}}{\delta z}
$$

with differences of the south-to-north $v$ and west-to-east $u$ wind components over a height range $\delta z$ of $60 \mathrm{~m}$ (two range gates).

From Eq. (1), high values of $\alpha_{\text {below }}$ represent rapidly increasing wind speeds within a short vertical distance from the surface to the jet nose and therefore a strong gradient (and vice versa). To investigate the turbulence characteristics depending on $\alpha_{\text {below }}, 30$-min standard deviations $\sigma_{w}$ of the vertical wind speed around the time of occurrence of the LLJ are derived as an indicator for turbulence. This can be accomplished because of the high temporal resolution of the vertical measurements. In addition, profiles of the horizontal wind speed and vector wind shear $U_{\text {shear }}$ [Eq. (2)] of the LLJ periods are extracted from the dataset. The profiles are averaged and scaled by the LLJ speed and height of the LLJ (Fig. 5).

The dataset of wind speed, wind shear, and $\sigma_{w}$ profiles during LLJ periods is classified according to the median of the $\alpha_{\text {below }}$ distribution $\left(0.02 \mathrm{~s}^{-1}\right.$; Fig. $\left.4 \mathrm{~b}\right)$ into lowgradient $\left(\alpha_{\text {below }}<0.02 \mathrm{~s}^{-1}\right)$ jets (Figs. 5a-d) and stronggradient jets, with $\alpha_{\text {below }}$ being higher than the median (Figs. 5e-h). The low-gradient jets reveal a median jetnose height of $465 \mathrm{~m}$ and a median wind speed of $8.7 \mathrm{~m} \mathrm{~s}^{-1}$. In comparison, the strong-gradient LLJs with $\alpha_{\text {below }}>0.02 \mathrm{~s}^{-1}$ show not only a lower jet-nose height $(315 \mathrm{~m})$ but also higher wind speeds $\left(10.2 \mathrm{~m} \mathrm{~s}^{-1}\right)$. The strong winds inhibit a further vertical growth of the stable layer and are caused by high nocturnal cooling rates and low geostrophic forcing (Baas et al. 2009). Also the stratification is more stable, resulting in a stronger decoupling; according to Emeis (2017) the magnitude of the wind shear in the subjet layer depends on the vertical temperature gradient below the jet.

For the low-gradient jets, $U_{\text {shear }}$ also remains small (Fig. 5b), which is expected because $U_{\text {shear }}$ and $\alpha_{\text {below }}$ are related to each other. Despite there being some variations in $U_{\text {shear }}$ with height, however, no significant turbulence can be seen below and above the jet (Fig. 5c). The strong-gradient LLJs in contrast show high averaged vector wind shear values ( $U_{\text {shear }}$ up to $0.04 \mathrm{~s}^{-1}$ ) below the jet nose in the region of strongly decreasing wind speeds with height. This result supports the findings of Svensson and Holtslag (2009), who showed a stronger turning of the wind for a shallower boundary layer height, which is here assumed to be related to the LLJ height. The strongest averaged turbulence (up to 

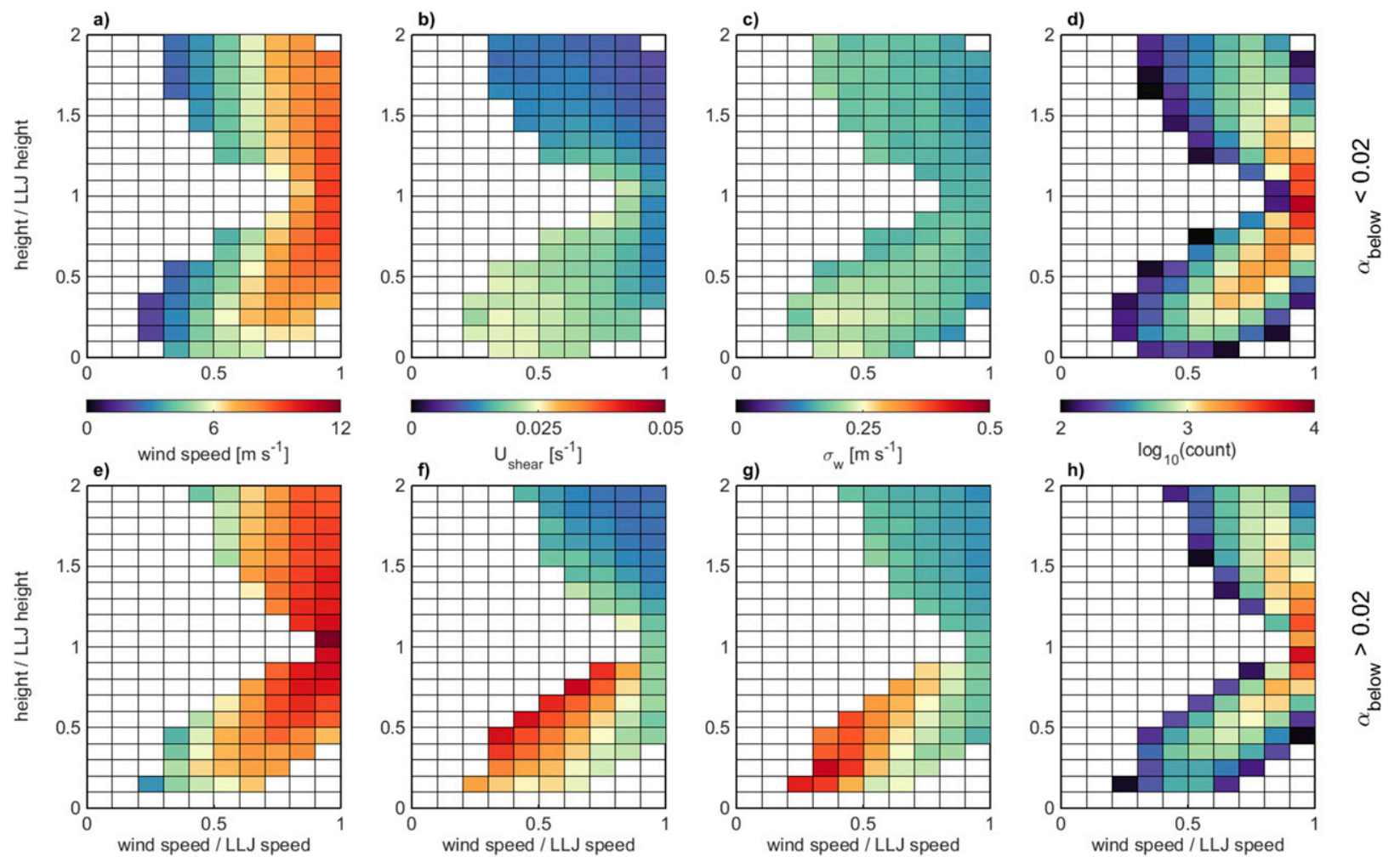

FIG. 5. Distributions of (a),(e) average wind speed, (b),(f) vector wind shear $U_{\text {shear }}$, (c),(g) vertical velocity standard deviation $\sigma_{w}$ calculated over $30 \mathrm{~min}$, and (d),(h) number of observations as a function of normalized wind speed (abscissa) and height (ordinate) of the LLJ for cases with (top) low and (bottom) strong wind shear. Only pixels with at least 100 measurements are shown.

$0.4 \mathrm{~m} \mathrm{~s}^{-1}$ ) can be found close to the surface below the region of high $U_{\text {shear }}$ values (Fig. $5 \mathrm{~g}$ ). Because of the low LLJ heights in this class, the mean height in the 0.1-0.2 height bin is $117.2 \mathrm{~m}$, which is within the rotor height of wind turbines.

\section{b. Influences on the surface fluxes}

Note that the lowest $105 \mathrm{~m}$ cannot be captured by the DWL. To get information about the differences in turbulence and transport processes closer to the surface, measurements from the EC station $5 \mathrm{~km}$ to the southeast of the JOYCE site are evaluated for nocturnal LLJ and no-LLJ periods when no clouds are detected by the DWL (Table 1). The cloud detection is based on a threshold value $\left(10^{-4} \mathrm{~m}^{-1} \mathrm{sr}^{-1}\right)$ of the attenuated backscatter measured by the DWL. The largest, statistically significant spread between the two data samples of LLJ and no-LLJ periods is observed during DJF, when there is less influence from the vegetation (maximum vegetation height of $0.4 \mathrm{~m}$ ) on the surface fluxes. The surface friction is also smaller, leading to decreased turbulent exchange processes.

The LLJ develops above the barrier for heat and momentum fluxes formed by the stable surface layer, as described in Businger (1973). Thereafter, the turbulence near the surface dissipates and strong wind shear associated with a generation of turbulence is present above the surface layer. This is shown in Fig. 5, where the turbulence occurs below the largest shear.

TABLE 1. Median flux values of latent and sensible heat, as well as the net ecosystem $\mathrm{CO}_{2}$ exchange, friction velocity, Monin-Obukhov stability parameter, standard deviation of the vertical velocity, air pressure, and $\mathrm{CO}_{2}$ content during periods without LLJs (second column) and with LLJs (third column). The data are obtained at a height of $2.46 \mathrm{~m}$ from the EC station using 30-min means during nighttime (from $1 \mathrm{~h}$ after sunset until $1 \mathrm{~h}$ before sunrise) in DJF between 2012 and 2016. Only times with no clouds identified by the DWL are considered. All distributions are statistically different as based on a $99 \%$ confidence interval.

\begin{tabular}{lcc}
\hline \hline & No LLJ (4039 cases) & LLJ (698 cases) \\
\hline LH $\left(\mathrm{W} \mathrm{m}^{-2}\right)$ & 6.25 & 0.65 \\
$\mathrm{SH}\left(\mathrm{W} \mathrm{m}^{-2}\right)$ & -23.97 & -11.73 \\
$\mathrm{NEE}\left(\mu \mathrm{mol} \mathrm{m}^{-2} \mathrm{~s}^{-1}\right)$ & 0.94 & 0.74 \\
$u_{*}\left(\mathrm{~m} \mathrm{~s}^{-1}\right)$ & 0.18 & 0.11 \\
$z / L$ & 0.06 & 0.16 \\
$\sigma_{w}\left(\mathrm{~m} \mathrm{~s}^{-1}\right)$ & 0.07 & 0.02 \\
$p_{\text {air }}(\mathrm{hPa})$ & 1006.61 & 1008.79 \\
$\mathrm{CO}_{2}(\mathrm{ppm})$ & 401.2 & 411.6 \\
\hline
\end{tabular}


The decoupling and reduction of turbulence at the surface during LLJ periods is reflected in the EC measurements by a decrease in the friction velocity $u_{*}$ and in the vertical velocity standard deviation relative to noLLJ periods. Also, the higher median value of 0.16 of the Monin-Obukhov stability parameter $z / L$ indicates a more stable regime during the presence of LLJs than during the no-LLJ cases (0.06), which reduces the exchange processes and increases the concentration of emitted gases. This is evident with regard to the increased $\mathrm{CO}_{2}$ value measured by the EC station during the LLJ periods (411.6 ppm). The increase of $10.4 \mathrm{ppm}$ relative to the no-LLJ periods accounts for more than $40 \%$ of the complete $\mathrm{CO}_{2}$ data-sample standard deviation. The accumulation of near-surface $\mathrm{CO}_{2}$ during the presence of an LLJ through an elevated wind shear layer acting as a barrier for surface-atmosphere exchange processes is in agreement with the findings of Mathieu et al. (2005).

Also, the latent heat flux $\mathrm{LH}$ of $0.65 \mathrm{~W} \mathrm{~m}^{-2}$ during the LLJ periods is much smaller than for the no-LLJ cases $\left(6.25 \mathrm{~W} \mathrm{~m}^{-2}\right)$. The sensible heat flux SH being closer to zero during LLJ cases and a decrease of more than $20 \%$ in the median net ecosystem $\mathrm{CO}_{2}$ exchange (NEE) supports the assumption of a decoupled surface layer in which all fluxes are reduced. The higher air pressure indicates a synoptic feature of a higher occurrence of LLJs during anticyclonic high pressure flow at this site between December and February.

The turbulence during the LLJ periods is not totally diminished because of an intermittent downward transport of momentum and turbulence, which was also found in EC measurements during LLJs in the study of Prabha et al. (2007). This interaction of the surface layer with the upper-level flow is defined by Mahrt and Vickers (2002) as an upside-down boundary layer. For a detailed study of these interaction processes, as well as a possible recoupling of the layers, tower measurements of the vertical turbulence structure below $100 \mathrm{~m}$ could be beneficial.

\section{LLJ interaction with the topography}

Because the influence of the surrounding topography is of high interest for the interpretation of wind measurements and their representativeness, the hypothesis of a significant effect on the wind field caused by small deviations from flat terrain is investigated in the following. The most prominent feature of the orography in the vicinity of the JOYCE site is a mine dump hill at a distance of approximately $1.8 \mathrm{~km}$ to the northeast of the DWL and around $200 \mathrm{~m}$ higher than the measurement site. Together with the open-pit mine, which is connected to the southeast of the hill, a heterogeneous orographic surrounding is present. The influence of the hill on the wind field is investigated by means of a case analysis during the HOPE campaign on 2 May 2013, where radiosondes and the ICON-LEM simulation are available for comparison with the DWL measurements.

On this day, with a sunset time of 1851 UTC, an easterly CWT is classified at 1800 UTC. After the breakdown of the convective boundary layer around 1630 UTC, the wind speed measured by the DWL increases below $600 \mathrm{~m}$ (Fig. 6a). After 1815 and 2130 UTC two LLJ periods are detected by the DWL, whereas from 1945 until 2130 UTC no further LLJs periods of at least $1 \mathrm{~h}$ are detected, since the coherence checks in the algorithm are not fulfilled. In this case the LLJ height between two consecutive profiles differs by more than $120 \mathrm{~m}$. Although the high wind speed is contained throughout the shown time period, the wind direction changes from northeast to southeast (Fig. 7). Therefore, the two detected LLJs can be seen as separate events.

The LLJ classification is also applied to the profiles of the ICON-LEM simulation. The coherence check of the time step between two consecutive wind speed maxima needs to be modified because of the different temporal resolution of the model. A new jet in the ICON-LEM LLJ detection is labeled when a gap of more than $18 \mathrm{~s}$ occurs, which is 2 times the output time and similar to the DWL LLJ detection, as described in section 3a. In that way, an LLJ is identified continuously from 1730 to 2200 UTC (Fig. 6b), which is more than $1 \mathrm{~h}$ earlier and more persistent than the DWL observations. When bringing the model data to the DWL resolution and applying the same thresholds as for the DWL, the coherent LLJ detection ends at 2015 UTC (Fig. 6c).

In general, the vertical extent and growth of the layer with increased wind speeds between 1730 and 1830 UTC is larger in ICON-LEM. The wind maximum is also sharper and higher in the model. ICON-LEM still captures the main features of the observed wind profiles, however, especially between 1815 and 1945 UTC, when an LLJ is detected by using the DWL observations and the model simulations. This motivates us to use the ICON-LEM simulations as a tool for the investigation of the spatial structure of the wind field.

\section{a. Influence of a scaled topography on the wind field in ICON-LEM}

Scaling the topography in the ICON-LEM simulations provides a valuable tool for analyzing the sensitivity of the wind field to heterogeneous terrain. 


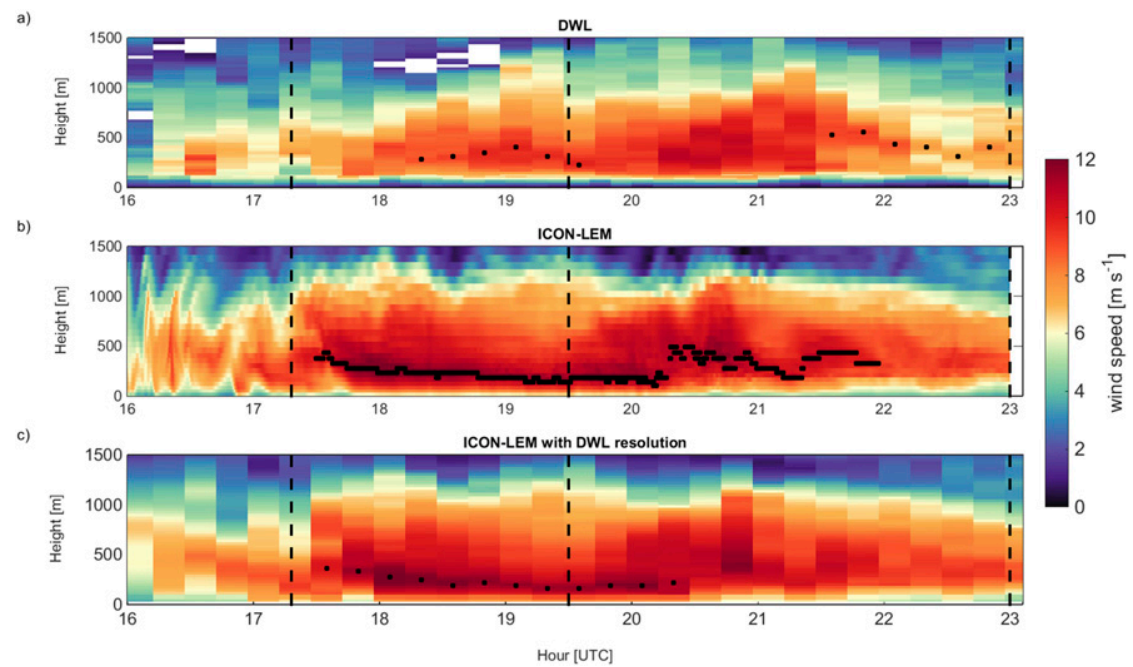

FIG. 6. Wind speed (a) measured by the DWL and tower and (b) simulated by ICON-LEM with an output every $9 \mathrm{~s}$ and (c) with the DWL resolution on 2 May 2013 [local time $=$ UTC + $1 \mathrm{~h}$ (winter) or $2 \mathrm{~h}$ (summer)]. The location of the LLJ height, detected by the LLJ classification, is marked with black dots. The vertical black dashed lines show the selected times for the case analysis in section 5c. Note that on this day the ICON-LEM simulation and the tower measurements are only available until 2300 UTC.

Therefore, streamlines are calculated on 2 May 2013 (2300 UTC) for the lowest 10 model levels of the 3D ICON-LEM simulations with the original topography, but also scaled by factors of 0.5 and 1.5 . The scaling factors are a reduction and increase, respectively, of $50 \%$ to ensure a significant difference in the model simulations with respect to the topographic effect on the wind field, which is still reasonable for the model setup. More extreme factors might enhance the spinup time or introduce artificial perturbations (because the initial data still include the orography implicitly), whereas less- strong scaling factors might not show any significant difference. During this time a southeasterly LLJ is present, which is shown to be likely connected to a channeling effect as described in section $4 a$.

When scaling down the topography by a factor of 0.5 , it is evident from Fig. $8 \mathrm{~b}$ that the wind field is less influenced by the orography across the whole domain. The wind speed increases faster with height than in the original simulation (Fig. 8a). The upscaled simulation shows a significant reduction in wind speed, however, especially close to the surface in the region of the

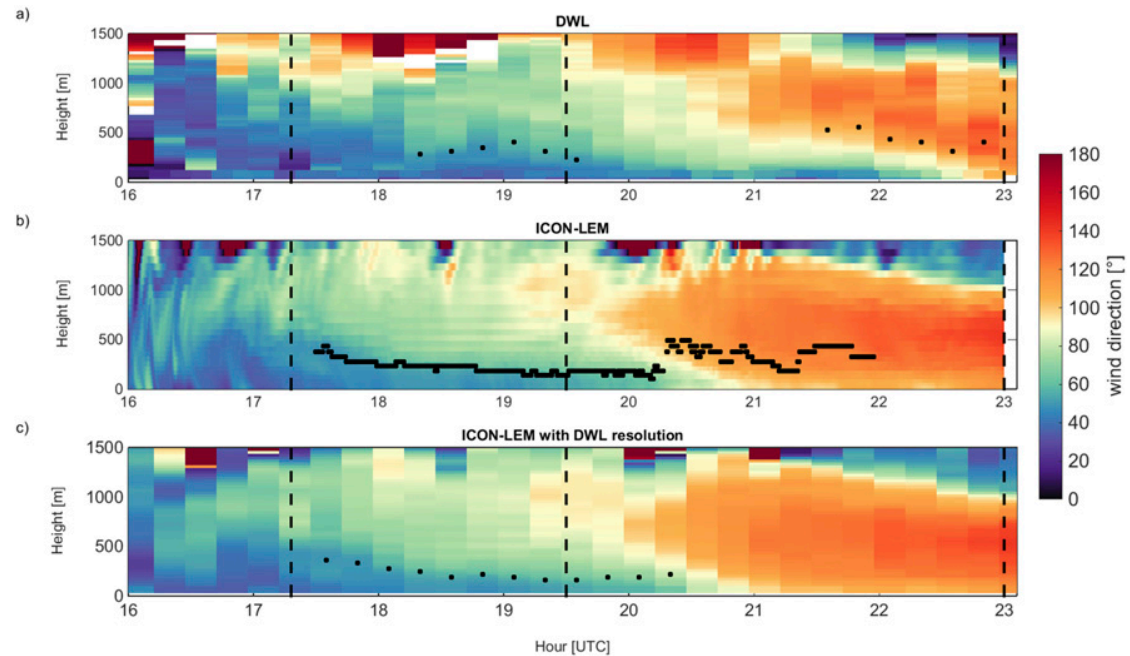

FIG. 7. As in Fig. 6, but for wind direction. 


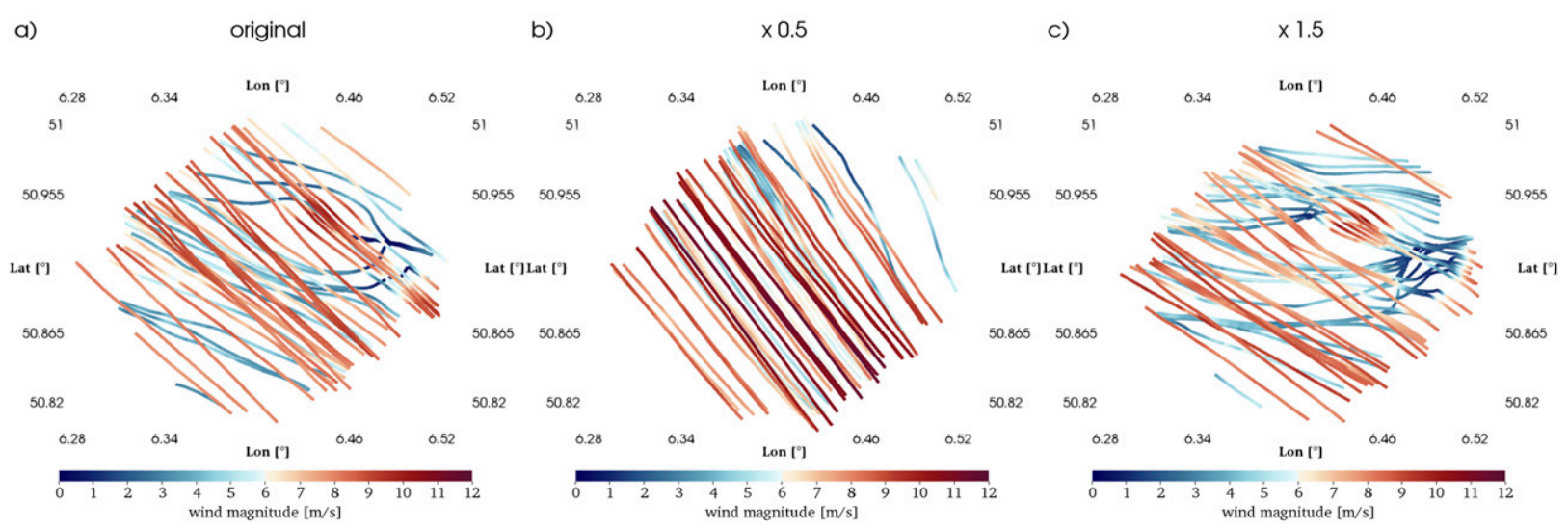

FIG. 8. Streamlines for the 3D ICON-LEM domain snapshot on 2 May 2013 (2300 UTC; southeasterly wind direction). The lowest 10 model levels (up to $790 \mathrm{~m} \mathrm{MSL}$ ) are shown, with the lowest wind speeds (blue) occurring close to the surface and increasing with height. Three simulations are conducted using (a) the original topography and topography that is scaled by factors of (b) 0.5 and (c) 1.5 .

open-pit mine (Fig. 8c). The wind speed then increases again over the top of the hill. The topography is also influencing the wind direction by up to $45^{\circ}$ for the lower elevations, which can be seen by the more easterly streamlines in the upscaled and original simulations. This finding indicates that the small but close hill to the northeast of the JOYCE site can act as an additional barrier to the channeling effect induced by the largescale topography surrounding the site.

\section{b. Comparison of observations and ICON-LEM for a nocturnal LLJ}

For a better comparison of the measurements and model output, profiles of wind speed, wind direction, vertical wind speed, and potential temperature around the time of the LLJ presence are shown in Fig. 9. Because the vertical velocity is highly variable in both space and time, the ICON-LEM and DWL profiles need to be averaged. The DWL vertical velocity measurements are therefore averaged to $30 \mathrm{~min}$. To account for a similar variability in the ICON-LEM vertical wind, but also to obtain simulated quantities that are comparable to the DWL scans, a spatial average of the model output is calculated. The $1.9 \times$ $1.9 \mathrm{~km}^{2}$ area around the JOYCE site (see the blackoutlined square in Fig. 10) is selected such that it covers the same area as the DWL scan during $30 \mathrm{~min}$ : winds with an average speed of $8 \mathrm{~m} \mathrm{~s}^{-1}$ (which is found during this time period) would travel $14 \mathrm{~km}$ during $30 \mathrm{~min}$. At $470 \mathrm{~m}$, which is approximately in the middle of the considered height range, the diameter of the DWL scan at $75^{\circ}$ elevation is $250 \mathrm{~m}$. This results in the same surface area as chosen for averaging the ICON-LEM output $(14 \mathrm{~km} \times$ $0.25 \mathrm{~km}=3.61 \mathrm{~km}^{2}=1.9 \times 1.9 \mathrm{~km}^{2}$ ). Three times are considered in the case analysis, including the LLJ initiation phase at 1720 UTC, the developed LLJ at 1930 UTC, and a weaker LLJ phase with a change of direction at 2300 UTC.
For the times 1720 and 2300 UTC profiles from radiosonde ascents are also available.

In general, the wind speed and direction profiles show good agreement (Figs. 9a,b,e,f,i,j), with only ICON-LEM overestimating the wind speed. In the evening transition period around 1720 UTC, turbulence is still present up to the mixing height at $285 \mathrm{~m}$ (dashed lines in Figs. 9a-d), defined as the height at which the standard deviation of the vertical velocity over $30 \mathrm{~min}$ drops below $0.4 \mathrm{~m} \mathrm{~s}^{-1}$, which can be used as an indicator for vertical mixing (Schween et al. 2014). Therefore, the 30-min standard deviation of the DWL is highest within the mixing layer (Fig. 9c). The turbulent motion, as well as the distance of the radiosonde launch site to the DWL, can explain parts of the deviations between the wind speed profiles below $300 \mathrm{~m}$. In addition, the launch site is located at the southeastern corner of the hill and is therefore not shaded from the northeasterly wind.

During the LLJ period at 1930 UTC (Figs. 9e-h) the turbulence only reaches up to $135 \mathrm{~m}$ and the LLJ has formed with a maximum wind speed of $9.8 \mathrm{~m} \mathrm{~s}^{-1}$ at $225 \mathrm{~m}$, as determined by the DWL (Fig. 9e). The wind direction close to the ground is still northeasterly, and it turns clockwise toward the geostrophic wind with height (Fig. 9f). For the ICON-LEM potential temperature profile, stable stratification can be identified, especially above the mixing-layer height from the DWL (Fig. 9h). The DWL shows increased positive vertical velocity values of up to $0.5 \mathrm{~m} \mathrm{~s}^{-1}$ around $600 \mathrm{~m}$, a result that is not captured by ICON-LEM.

With a change in near-surface wind direction to southeasterly at 2300 UTC (Fig. 9j), the distinct LLJ profile vanishes together with the vertical updraft (Figs. 9i,k). The potential temperature profile measured by the RS shows a stable surface layer up to about $150 \mathrm{~m}$ and a neutral stratified layer until $600 \mathrm{~m}$, followed again 

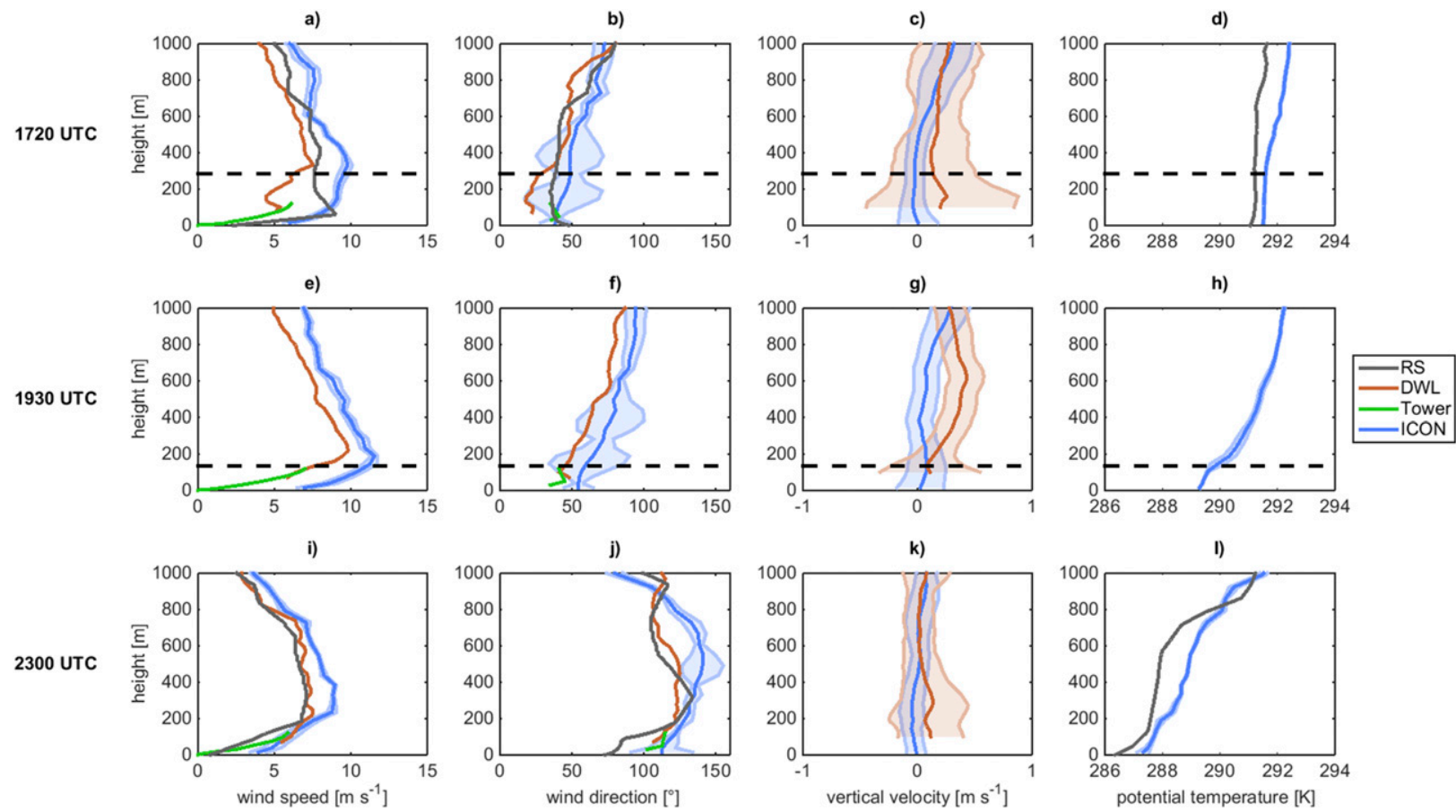

FIG. 9. Case analysis on 2 May 2013 with profiles of (a),(e),(i) wind speed, (b),(f),(j) wind direction, (c),(g),(k) vertical velocity, and (d),(h),(l) potential temperature. The measurements from RSs (gray line), DWL (red line), and the tower (green line), as well as the ICON-LEM output (blue line), are shown for (top) 1720, (middle) 1930, and (bottom) 2300 UTC. The ICON-LEM profiles are spatially averaged over $1.9 \mathrm{~km} \times 1.9 \mathrm{~km}$ and the standard deviation [for wind direction calculated with the method of Yamartino (1984)] is shaded in light blue. The DWL vertical velocity is temporally averaged over $30 \mathrm{~min}$, with the standard deviation given in reddish shading. The mixing-layer height after Schween et al. (2014) is shown by a black dashed line.

by a stable layer. This might indicate a decoupling at the surface from the adjacent residual layer reaching up to $600 \mathrm{~m}$. These are favorable conditions for an LLJ, which is also detected using the DWL measurements.

\section{c. Topographic influence on the vertical wind}

To understand the differences in the vertical wind between ICON-LEM and the DWL, the vertical velocity of the 3D ICON-LEM domain is evaluated at $300 \mathrm{~m}$ MSL (Fig. 10). This height is chosen to be above the highest surface point in the model domain. During the LLJ period at 1930 UTC the vertical velocities simulated by ICON-LEM reveal updrafts on the windward side and downdraft motions leeward of the hill with the wind coming from the northeast (Fig. 10b). Thus, the orographic disturbance induces vertical wind

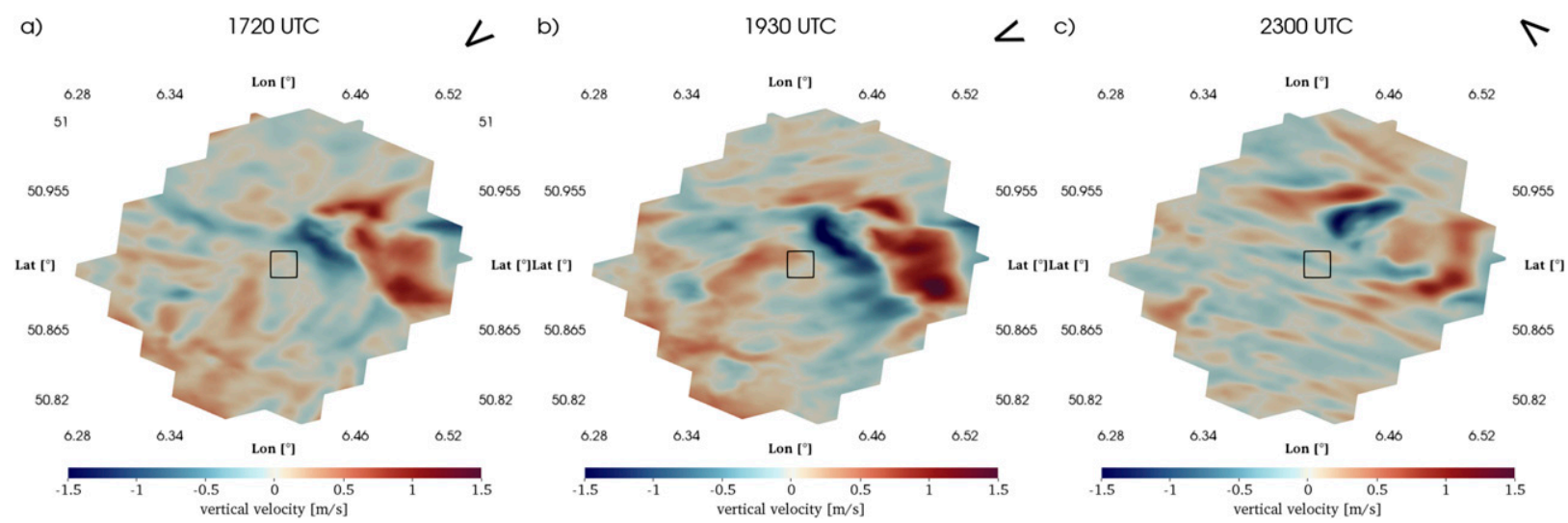

FIG. 10. Vertical velocity at $300 \mathrm{~m}$ MSL of the ICON-LEM domain snapshots at (a) 1720, (b) 1930, and (c) 2300 UTC 2 May 2013 . The black-outlined square denotes the $1.9 \mathrm{~km} \times 1.9 \mathrm{~km}$ area around the JOYCE site, where the average vertical velocity profiles from Fig. 9 are calculated. The black arrow in the top-right corner of (a)-(c) shows the wind direction at JOYCE around $300 \mathrm{~m}$. 
a)

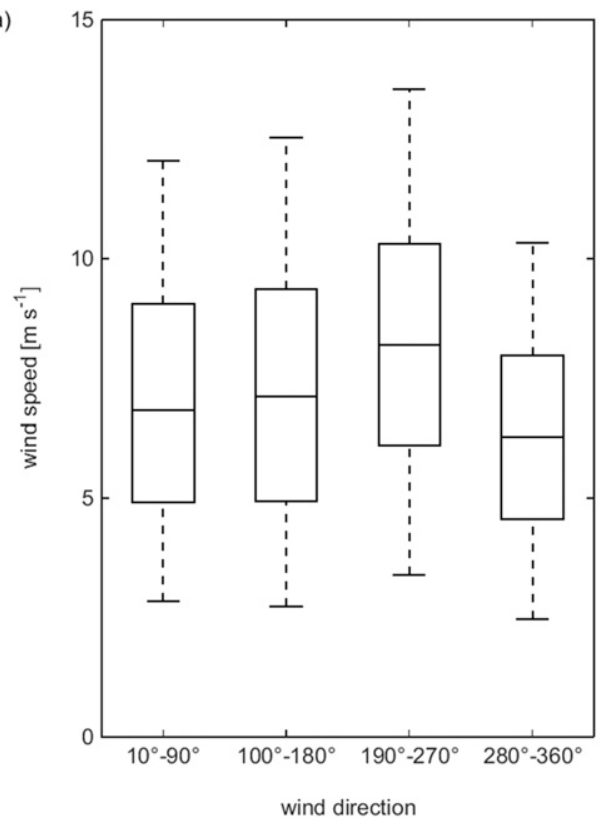

b)

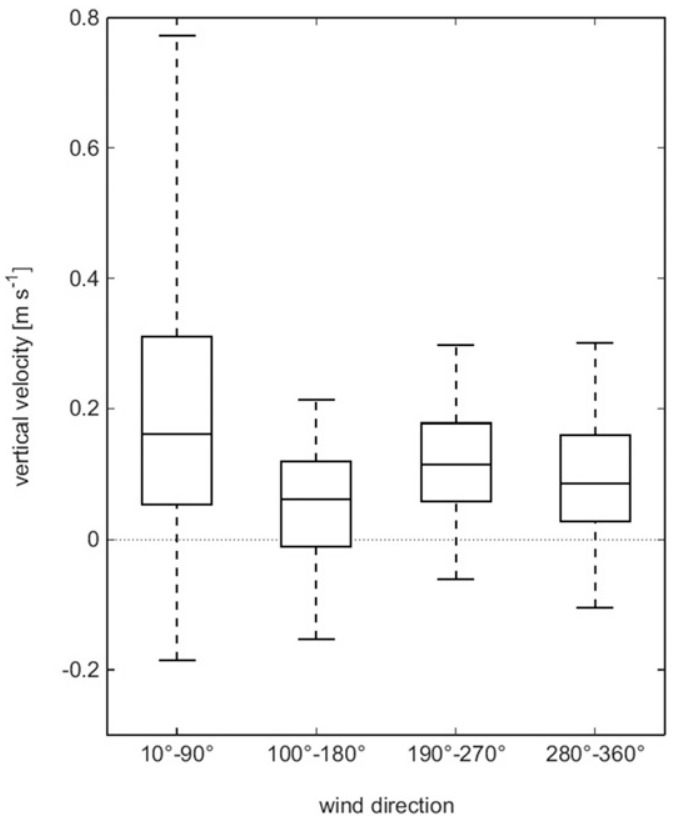

FIG. 11. Box plots showing the 5th, 25th, 50th, 75th, and 95th percentiles of (a) wind speed and (b) 30-min averages of the vertical velocity measured by the DWL between 225 and $705 \mathrm{~m}$. Only LLJs below $500 \mathrm{~m}$ during nighttime (from $1 \mathrm{~h}$ after sunset until $1 \mathrm{~h}$ before sunrise) and clear-sky (DWL backscatter $<10^{-4} \mathrm{~m}^{-1} \mathrm{sr}^{-1}$ ) conditions are included. The wind speed between 105 and $225 \mathrm{~m}$ needs to be above $4 \mathrm{~m} \mathrm{~s}^{-1}$, and the data are binned according to the wind direction (bin size $=80^{\circ}$ ) in this range with $10^{\circ}$ separation. The numbers of cases are 1310 $\left(10^{\circ}-90^{\circ}\right), 2564\left(100^{\circ}-180^{\circ}\right), 2142\left(190^{\circ}-270^{\circ}\right)$, and $525\left(280^{\circ}-360^{\circ}\right)$.

variations up to approximately $3 \mathrm{~m} \mathrm{~s}^{-1}$, with the JOYCE site located in an updraft region, as also was seen by the DWL (Fig. 9g). The strong gradients in the ICON-LEM vertical wind field can explain the deviations to the observations by a slight spatial displacement. At 2300 UTC the simulated spatial pattern in the vertical velocity (Fig. 10c) is changed according to the turning of the wind direction and a wavelike structure is visible, caused by the wind first flowing down the depression of the pit mine and then uphill.

The results of the case analysis suggest that the updrafts measured at the JOYCE site are caused by the topography for northeasterly winds. In the following, we investigate if this statement can be verified using long-term measurements. Therefore, the DWL dataset from 2012 to 2016 is sampled for LLJs below $500 \mathrm{~m}$ during clear-sky conditions, since drizzle events could influence the vertical velocity estimates. Furthermore, it is required that the wind speed between 105 and $225 \mathrm{~m}$ exceeds $4 \mathrm{~m} \mathrm{~s}^{-1}$ to ensure a sufficiently strong updraft. Convective motions are excluded by only considering nighttime cases. The data sample of wind speed and 30-min averages of the vertical wind above the summit of the hill (from 225 to $705 \mathrm{~m}$ ) is classified into different directional classes to investigate the effect of the hill to the northeast $\left(10^{\circ}-90^{\circ}\right)$ relative to the other directions (Fig. 11).
The wind speed distribution of the direction in the range of $190^{\circ}-270^{\circ}$ reveals higher values, with a median value of $8.2 \mathrm{~m} \mathrm{~s}^{-1}$ that exceeds the median values in the other directional classes by $1.1-1.9 \mathrm{~m} \mathrm{~s}^{-1}$ (Fig. 11a). Although the effect is small relative to the range of observed wind speed values (standard deviation around $3 \mathrm{~m} \mathrm{~s}^{-1}$ ), a possible explanation could be the influence of frontal systems predominantly coming from the southwest.

Despite lower wind speeds, a significant shift to higher positive vertical wind speed values and by far the highest variability can be found in the $10^{\circ}-90^{\circ}$ directional class (Fig. 11b). The 75 th percentile $\left(0.3 \mathrm{~m} \mathrm{~s}^{-1}\right)$ of the $10^{\circ}-90^{\circ}$ class is around or even higher than the 95th percentiles of the other distributions. The longer tail toward negative vertical velocity values observed for the northeasterly wind directions could be explained by a slight shift of the updraft region after the descending motions at the leeward side of the hill, as seen in the ICON-LEM simulation, or a higher degree of turbulence induced by the topography. The overall shift to positive values indicated by all distributions of the vertical velocity is probably due to a small offset of the instrument on the order of a few centimeters per second. It can be conclusively stated from the model simulations and the DWL observations that the moderate topography around JOYCE shows sufficient heterogeneity to cause significant disturbances in the wind field. 


\section{Summary and conclusions}

The LLJ climatology obtained from the long-term observations (March 2012-December 2016) by the Doppler wind lidar at the JOYCE site in western Germany shows a clear diurnal cycle of the occurrence of LLJs, favoring the nighttime appearance of the jets. In total, LLJs are detected in $13 \%$ of the observational period. Seasonal differences in the diurnal LLJ frequency of occurrence can mostly be attributed to the length of the day. Fewer but stronger LLJs occur in the winter months, because of the lower temperature gradients between day and night and strong geostrophic forcing. An analysis of the synoptic situation using circulation weather types showed that the predominant southwesterly direction of the jets is in agreement with the general circulation around JOYCE. The southeasterly LLJs cannot be associated with the synoptic forcing but rather are more related to a local channeling effect.

The turbulent characteristics of the LLJs, provided by the Doppler wind lidar, showed notably higher vector wind shear below the jet nose for LLJs with strongly decreasing wind speeds below the jet. When dividing all LLJs according to the bulk wind shear, significant turbulent motions can only be found close to the surface for jets with high bulk wind shear. The characterization of the turbulence associated with LLJs shows the importance for wind-energy production, since a large number of LLJs (2965; $16 \%$ of all jets) are detected in the range of the rotor height below $200 \mathrm{~m}$.

Evaluation of the nighttime EC-station measurements proves the concept of Businger (1973) of a decoupled surface layer during LLJ events. The strong wind shear associated with the LLJ together with the nonturbulent stable layer hampers upward mixing, which leads to an accumulation of carbon dioxide $\left(\mathrm{CO}_{2}\right)$ and a reduction of the heat and momentum fluxes in the stable surface layer. Turbulent mixing found at the surface might be generated by a recoupling of the flow through intermittent downward transport of jet-induced turbulence. This concept of an upside-down boundary layer is explained by Mahrt and Vickers (2002) and could be further analyzed using detailed measurements of the vertical structure of nearsurface turbulence.

In the comprehensive case analysis, a strong interaction of the winds with the topography, dominated by a 200-mhigh hill and a pit mine close to the measurement site, can be observed during an LLJ event. The DWL shows high positive vertical velocities for northeasterly LLJs, when the wind is flowing over the hill toward the instrument's field of view. High-resolution simulations of ICON-LEM, as a self-consistent representation of the atmosphere, help in the analysis of the spatial variations of the wind field. The vertical velocities reveal a wave structure induced by the hill and pit mine, which are also influencing the wind speed and direction. From a long-term perspective, this influence introduces a much stronger variability in the vertical wind for the location of the DWL, depending on the wind direction.

The results of the long-term assessment, as well as the model simulations presented in this study, stress the importance of analyzing LLJs and their local effects. The LLJ identification algorithm of Tuononen et al. (2017) proved to be able to identify LLJs objectively by utilizing a multiyear dataset of high temporal and vertical resolution Doppler lidar measurements. The method can further be used for evaluating model performance in terms of the correct representation of LLJ characteristics. By including additional information on atmospheric turbulence, which can be derived from Doppler wind lidars, the impact of LLJs on wind turbines can be examined.

Acknowledgments. The authors acknowledge the Transregional Collaborative Research Centre (TR32) "Patterns in Soil-Vegetation-Atmosphere Systems" funded by the German Science Foundation (DFG), which has continuously contributed to the instrumentation of JOYCE and its maintenance as well as funding T. Marke. The measurement infrastructure providing EC data was supported by the Terrestrial Environmental Observatories (TERENO), funded by the Helmholtz Association. Part of the work has been granted by Energy Transition and Climate Change (ET-CC) under DFG Grant ZUK 81. The ICON-LEM simulations are incorporated by the $\mathrm{HD}(\mathrm{CP})^{2}$ research initiative funded by the German Ministry for Education and Research (BMBF). Furthermore, the authors gratefully acknowledge the computing time granted by the John von Neumann Institute for Computing and provided on the supercomputer JURECA at the JSC. Access to the meteorological tower observations was made possible through Axel Knaps from the Research Centre Jülich. The work of M. Tuonnonen is funded by the Maj and Tor Nessling Foundation (Grants 201500300 and 201600003).

\section{REFERENCES}

Ayachit, U., 2015: The ParaView Guide: A Parallel Visualization Application. Kitware, Inc., 340 pp.

Baas, P., F. C. Bosveld, H. Klein Baltink, and A. A. M. Holtslag, 2009: A climatology of nocturnal low-level jets at Cabauw. J. Appl. Meteor. Climatol., 48, 1627-1642, https://doi.org/ 10.1175/2009JAMC1965.1.

Baldauf, M., A. Seifert, J. Förstner, D. Majewski, M. Raschendorfer, and T. Reinhardt, 2011: Operational convective-scale numerical weather prediction with the COSMO model: Description and sensitivities. Mon. Wea. Rev., 139, 3887-3905, https://doi.org/ 10.1175/MWR-D-10-05013.1. 
Banta, R., R. K. Newsom, J. K. Lundquist, Y. L. Pichugina, R. L. Coulter, and L. Mahrt, 2002: Nocturnal low-level jet characteristics over Kansas during CASES-99. Bound-Layer Meteor., 105, 221-252, https://doi.org/10.1023/A:1019992330866.

Blackadar, A. K., 1957: Boundary layer wind maxima and their significance for the growth of nocturnal inversions. Bull. Amer. Meteor. Soc., 38, 283-290.

Bonner, W. D., 1968: Climatology of the low level jet. Mon. Wea. Rev., 96, 833-850, https://doi.org/10.1175/1520-0493(1968)096<0833: COTLLJ $>2.0 . \mathrm{CO} ; 2$.

Businger, J. A., 1973: Turbulent transfer in the atmospheric surface layer. Workshop on Micrometerology, D. H. Haugen, Ed., Amer. Meteor. Soc., 67-100.

Dee, D. P., and Coauthors, 2011: The ERA-Interim reanalysis: Configuration and performance of the data assimilation system. Quart. J. Roy. Meteor. Soc., 137, 553-597, https://doi.org/ 10.1002/qj.828.

Dipankar, A., B. Stevens, R. Heinze, C. Moseley, G. Zängl, M. Giorgetta, and S. Brdar, 2015: Large eddy simulation using the general circulation model ICON. J. Adv. Model. Earth Syst., 7, 963-986, https://doi.org/10.1002/2015MS000431.

Dörenkämper, M., M. Optis, A. Monahan, and G. Steinfeld, 2015: On the offshore advection of boundary-layer structures and the influence on offshore wind conditions. Bound.-Layer Meteor., 155, 459-482, https://doi.org/10.1007/s10546-015-0008-x.

Emeis, S., 2017: Upper limit for wind shear in stably stratified conditions expressed in terms of a bulk Richardson number. Meteor. Z., 26, 421-430, https://doi.org/10.1127/metz/ 2017/0828.

_- M. Harris, and R. M. Banta, 2007: Boundary-layer anemometry by optical remote sensing for wind energy applications. Meteor. Z., 16, 337-347, https://doi.org/10.1127/ 0941-2948/2007/0225.

Heinze, R., and Coauthors, 2017: Large-eddy simulations over Germany using ICON: A comprehensive evaluation. Quart. J. Roy. Meteor. Soc., 143, 69-100, https://doi.org/10.1002/ qj.2947.

Higgins, R. W., Y. Yao, E. S. Yarosh, J. E. Janowiak, and K. C. Mo, 1997: Influence of the Great Plains low-level jet on summertime precipitation and moisture transport over the central United States. J. Climate, 10, 481-507, https://doi.org/10.1175/ 1520-0442(1997)010<0481:IOTGPL > 2.0.CO;2.

Hirsikko, A., and Coauthors, 2014: Observing wind, aerosol particles, cloud and precipitation: Finland's new ground-based remote-sensing network. Atmos. Meas. Tech., 7, 1351-1375, https://doi.org/10.5194/amt-7-1351-2014.

Holtslag, A. A. M., and Coauthors, 2013: Stable atmospheric boundary layers and diurnal cycles: Challenges for weather and climate models. Bull. Amer. Meteor. Soc., 94, 1691-1706, https://doi.org/10.1175/BAMS-D-11-00187.1.

Jenkinson, A. F., and F. P. Collison, 1977: An initial climatology of gales over the North Sea. Met Office Synoptic Climatology Branch Memo. 62, 18 pp.

Krause, D., and P. Thörnig, 2016: JURECA: General-purpose supercomputer at Jülich Supercomputing Centre. J. LargeScale Res. Facil., 2, A62, https://doi.org/10.17815/jlsrf-2-121.

Lampert, A., B. Bernalte Jimenez, G. Gross, D. Wulff, and T. Kenull, 2015: One-year observations of the wind distribution and low-level jet occurrence at Braunschweig, north German plain. Wind Energy, 19, 1807-1817, https://doi.org/ 10.1002/we.1951.

_ - and Coauthors, 2016: A study of local turbulence and anisotropy during the afternoon and evening transition with an unmanned aerial system and mesoscale simulation. Atmos. Chem. Phys., 16, 8009-8021, https://doi.org/10.5194/acp-16-8009-2016.

Löhnert, U., and Coauthors, 2015: JOYCE: Jülich Observatory for Cloud Evolution. Bull. Amer. Meteor. Soc., 96, 1157-1174, https://doi.org/10.1175/BAMS-D-14-00105.1.

Macke, A., and Coauthors, 2017: The $\mathrm{HD}(\mathrm{CP})^{2}$ Observational Prototype Experiment (HOPE)-An overview. Atmos. Chem. Phys., 17, 4887-4914, https://doi.org/10.5194/acp-17-4887-2017.

Mahrt, L., and D. Vickers, 2002: Contrasting vertical structures of nocturnal boundary layers. Bound.-Layer Meteor., 105, 351363, https://doi.org/10.1023/A:1019964720989.

Mathieu, N., I. Strachan, M. Leclerc, A. Karipot, and E. Pattey, 2005: Role of low-level jets and boundary-layer properties on the NBL budget technique. Agric. For. Meteor., 135, 35-43, https://doi.org/10.1016/j.agrformet.2005.10.001.

Mauder, M., M. Cuntz, C. Drüe, A. Graf, C. Rebmann, H. P. Schmid, M. Schmidt, and R. Steinbrecher, 2013: A strategy for quality and uncertainty assessment of long-term eddy-covariance measurements. Agric. For. Meteor., 169, 122-135, https://doi.org/10.1016/j.agrformet.2012.09.006.

Mitchell, M. J., R. W. Arritt, and K. Labas, 1995: A climatology of the warm season Great Plains low-level jet using wind profiler observations. Wea. Forecasting, 10, 576-591, https://doi.org/ 10.1175/1520-0434(1995)010<0576:ACOTWS $>2.0 . C O ; 2$.

O'Connor, E. J., A. J. Illingworth, I. M. Brooks, C. D. Westbrook, R. J. Hogan, F. Davies, and B. J. Brooks, 2010: A method for estimating the turbulent kinetic energy dissipation rate from a vertically pointing Doppler lidar, and independent evaluation from balloon-borne in situ measurements. J. Atmos. Oceanic Technol., 27, 1652-1664, https://doi.org/ 10.1175/2010JTECHA1455.1.

Päschke, E., R. Leinweber, and V. Lehmann, 2015: An assessment of the performance of a $1.5 \mu \mathrm{m}$ Doppler lidar for operational vertical wind profiling based on a 1-year trial. Atmos. Meas. Tech., 8, 2251-2266, https://doi.org/10.5194/ amt-8-2251-2015.

Pearson, G., F. Davies, and C. Collier, 2009: An analysis of the performance of the UFAM pulsed Doppler lidar for observing the boundary layer. J. Atmos. Oceanic Technol., 26, 240-250, https://doi.org/10.1175/2008JTECHA1128.1.

Peña, A., and Coauthors, 2016: Ten years of boundary-layer and wind-power meteorology at Høvsøre, Denmark. Bound.-Layer Meteor., 158, 1-26, https://doi.org/10.1007/ s10546-015-0079-8.

Philipp, A., C. Beck, R. Huth, and J. Jacobeit, 2016: Development and comparison of circulation type classifications using the COST 733 dataset and software. Int. J. Climatol., 36, 26732691, https://doi.org/10.1002/joc.3920.

Prabha, T. V., M. Y. Leclerc, A. Karipot, and D. Y. Hollinger, 2007: Low-frequency effects on eddy covariance fluxes under the influence of a low-level jet. J. Appl. Meteor. Climatol., 46, 338352, https://doi.org/10.1175/JAM2461.1.

Schween, J. H., A. Hirsikko, U. Löhnert, and S. Crewell, 2014: Mixing-layer height retrieval with ceilometer and Doppler lidar: From case studies to long-term assessment. Atmos. Meas. Tech., 7, 3685-3704, https://doi.org/10.5194/amt-7-3685-2014.

Stensrud, D., 1996: Importance of low-level jets to climate: A review. J. Climate, 9, 1698-1711, https://doi.org/10.1175/ 1520-0442(1996)009<1698:IOLLJT>2.0.CO;2.

Storm, B., J. Dudhia, S. Basu, A. Swift, and I. Giammanco, 2009: Evaluation of the Weather Research and Forecasting Model on forecasting low-level jets: Implications for wind energy. Wind Energy, 12, 81-90, https://doi.org/10.1002/we.288. 
Su, J., M. Felton, L. Lei, M. P. McCormick, R. Delgado, and A. St. Pé, 2016: Lidar remote sensing of cloud formation caused by low-level jets: Cloud formation caused by low-level jets. J. Geophys. Res. Atmos., 121, 5904-5911, https://10.1002/ 2015JD024590.

Svensson, G., and A. A. M. Holtslag, 2009: Analysis of model results for the turning of the wind and related momentum fluxes in the stable boundary layer. Bound.-Layer Meteor., 132, 261277, https://doi.org/10.1007/s10546-009-9395-1.

Tuononen, M., V. A. Sinclair, and T. Vihma, 2015: A climatology of low-level jets in the mid-latitudes and polar regions of the Northern Hemisphere: A climatology of low-level jets. Atmos. Sci. Lett., 16, 492-499, https://doi.org/10.1002/asl.587.

, E. J. O'Connor, V. A. Sinclair, and V. Vakkari, 2017: Lowlevel jets over Utö, Finland, based on Doppler lidar observations. J. Appl. Meteor. Climatol., 56, 2577-2594, https:// doi.org/10.1175/JAMC-D-16-0411.1.

Whiteman, C. D., X. Bian, and S. Zhong, 1997: Low-level jet climatology from enhanced rawinsonde observations at a site in the southern
Great Plains. J. Appl. Meteor., 36, 1363-1376, https://doi.org/ 10.1175/1520-0450(1997)036<1363:LLJCFE > 2.0.CO;2.

Yamartino, R. J., 1984: A comparison of several single-pass estimators of the standard deviation of wind direction. J. Climate Appl. Meteor., 23, 1362-1366, https://doi.org/10.1175/15200450(1984)023<1362:ACOSPE > 2.0.CO;2.

Zängl, G., D. Reinert, P. Rípodas, and M. Baldauf, 2015: The ICON (ICOsahedral Non-hydrostatic) modelling framework of DWD and MPI-M: Description of the non-hydrostatic dynamical core. Quart. J. Roy. Meteor. Soc., 141, 563-579, https:// doi.org/10.1002/qj.2378.

Zhong, S., J. D. Fast, and X. Bian, 1996: A case study of the Great Plains low-level jet using wind profiler network data and a high-resolution mesoscale model. Mon. Wea. Rev., 124, 785-806, https://doi.org/ 10.1175/1520-0493(1996)124<0785:ACSOTG>2.0.CO;2.

Zhou, B., and F. K. Chow, 2012: Turbulence modeling for the stable atmospheric boundary layer and implications for wind energy. Flow Turbul. Combust., 88, 255-277, https://doi.org/ 10.1007/s10494-011-9359-7. 